\title{
CLUSTERING PENCAPAIAN TARGET PENJUALAN RUMAH PARA KARYAWAN MARKETING MENGGUNAKAN RAPID MINER DAN ALGORITMA K-MEANS
}

\author{
Muhammad Fahmi Julianto ${ }^{1}$, Sofian Wira Hadi ${ }^{2}$, Setiaji ${ }^{3}$, Windu Gata ${ }^{4}$, Rangga Pebrianto ${ }^{5}$ \\ STMIK Nusa Mandiri ${ }^{1,2,3,4,5}$ \\ 14002389@nusamandiri.ac.id ${ }^{1}, 14002361 @$ nusamandiri.ac.id ${ }^{2}$, setiaji.sej@nusamandiri.ac.id ${ }^{3}$, \\ windu@nusamandiri.ac.id ${ }^{4}, 14002396 @$ nusamandiri.ac.id ${ }^{5}$
}

\begin{abstract}
Abstrak - Dalam persaingan dunia bisnis saat ini, kita dituntut untuk senantiasa mengembangkan bisnis agar selalu bertahan dalam persaingan . Fachry PropertyLand merupakan salah satu bidang usaha yang fokus di bidang property. Di mana toko ini memenuhi kebutuhan konsumen yang sedang trend saat ini. Pada Fachry Property Land terdapat beberapa permasalahan yang selalu muncul terkait penjualan. Dimana banyak karyawan yang tidak memenuhi target penjualannya. Berdasarkan hal tersebut maka diharapkan bisa mepermudah pihak Fachry Property Land dalam menilai kelayakan atas karyawannya dalam menentukan karyawan yang memenuhi target, belum memenuhi target dan tidak memenuhi target, dalam proses pengelompokan maka akan digunakan sebuah metode pengelompokan menggunakan Algoritma K-Means Clustering dengan implementasinya menggunakan sebuah software Data Mining yaitu, RapidMiner Studio versi 9.2. Dengan adanya aplikasi Rapid Miner Studio ini diharapkan pemilik Fachry Propertyland dapat melihat hasil pengelompokkan karyawan yang memenuhi target, belum memenuhi target dan tidak memenuhi target. Sehingga pemilik Fachry Propertyland dapat melakukan tindakan kepada karyawannya tersebut.

Kata Kunci : Clustering, Rapid Miner, K-Means
\end{abstract}

\begin{abstract}
In the competition of the business world today, we are required to always develop business in order to always be successful in competition. Fachry PropertyLand is one of the business fields engaged in the sale of homes. Everywhere this shop must meet the needs of customers who are currently trending. On Land Fachry Property Around the issue that always appears regarding sales. Where many employees do not meet their sales targets. Based on this, it is expected to facilitate the Land Fachry Property in assessing the appropriateness of its employees in determining employees who have met the target, has not met the target and does not meet the target, in the grouping process, the grouping method will be used using the K-Me Clustering Algorithm as a method of manual replacement and in its implementation the Data Mining software uses RapidMiner Studio version 9.2. With the application of Rapid Miner Studio, it is expected that the owner of Fachry Propertyland can see the results of the grouping that meets the target, does not meet the target and does not meet the target. It is expected that the owner of Fachry Propertyland can take action on these employees.

Keywords: Clustering, Rapid Miner, K-Means
\end{abstract}

\section{PENDAHULUAN}

Kemajuan teknologi informasi pada saat ini sudah semakin berkembang pesat disegala aspek bidang kehidupan. Banyak sekali data yang diperoleh dari teknologi informasi yang canggih, mulai dari bidang industri, ekonomi, ilmu dan teknologi maupun berbagai aspek kehidupan lainnya. Dalam persaingan dunia bisnis saat ini, kita dituntut untuk senantiasa mengembangkan bisnis agar selalu bertahan dalam persaingan (M.Hasyim Siregar, S.Kom., 2018). Fachry PropertyLand merupakan salah satu bidang usaha yang fokus di bidang Property. Dimana toko ini harus memenuhi kebutuhan konsumen yang sedang trend saat ini. untuk dapat melakukan hal tersebut, maka mebutuhkan sumber informasi untuk dapat dianalisa lebih lanjut. Pada Fachry Property Land terdapat beberapa permasalahan yang selalu muncul mengenai penjualan. Berdasarkan hal tersebut maka penulis berharap bisa mempermudah pihak Fachry Property Land dalam menilai kelayakan atas karyawannya dalam pencapaian target penjualan. Tidak hanya itu penulis juga mengharapkan bisa memberikan rangsangan kepada pengelolah data supaya lebih efesien dalam menggali informasi yang dibutuhkan oleh Fachry Property Land, sehingga bisa menjawab kebutuhan dari perusahaan tersebut. Penulis berharap dapat membantu memberikan informasi mengenai hasil pengklasteran data karyawan yang memenuhi target dan tidak memenuhi target penjualan. Dengan demikian, dibutuhkan analisia yang menggunakan software data mining guna menunjang arus data dan informasi sesuai dengan kebutuhan dari proses-proses tersebut. Knowledge discovery in Database (KDD) didefinisikan sebagai ekstraksi informasi potensial, implisit dan tidak dikenal dari sekumpulan data. Proses KDD menghasilkan sebuah proses data mining (proses mengekstrak kecenderungan pola suatu data), kemudian mengubah hasil 
tersebut secara akurat menjadi suatu informasi yang mudah dipahami(Asroni Asroni, 2015). Proses KDD secara garis besar terdiri dari Data Selection, Pre-processing/Cleaning, Transformation, Data mining, dan Interpretation / Evaluation. Algoritma K-Means merupakan algoritma non hirarki yang berasal dari metode data clustering. metode K-Means ini membagi data kedalam kelompok sehingga data Mempunyai karakteristik sama dimasukan kedalam satu kelompok yang sama dan data yang berkarakteristik berbeda dikelompokkan kedalam kelompok yang lain(Prasetyo, 2012). Menerapkan algoritma pengelompokan k-means tradisional dan jarak pengukuran Euclidean dari kesamaan dipilih untuk digunakan dalam analisis nilai (Garg, 2016). Algoritma K-means dapat bekerja dengan baik untuk beberapa dokumen tertentu (Jayant Tikmani, Sudhanshu Tiwari, 2015). Adapun tujuan dari diadakannya pengelompokan data ini adalah untuk meminimalkan fungsi objektif yang diset dalam proses pengelompokan, yang pada umumnya berusaha meminimalkan varias didalam suatu kelompok dan memaksimalkan variasi antar kelompok pemilihan metode $\mathrm{K}$ Means dikarenakan metode ini harus menggunakan data fisik yang bersifat jelas, hal ini sesuai dengan data yang akan digunakan pada permasalahan di dalam pengelompokan penjualan property. Selain itu, metode ini bersifat fleksibel karena pengguna dapat menentukan jumlah Kluster yang akan dibuat(Mardalius, 2018). Pada penelitian ini analisa data mining dilakukan dengan menggunakan metode K-Means clustering. Dengan menggunakan metode ini, data yang sudah didapatkan dapat dibagi kedalam beberapa cluster berdasarkan kemiripan dari data-data tersebut, sehingga data yang mempunyai karakteristik yang sama dikelompokan dalam satu cluster dan yang memliki karakteristik yang berbeda dikelompokan dalam cluster yang lain yang memiliki karakteristik yang sama (Ong, 2013).

\section{METODOLOGI PENELITIAN}

Dalam metode penelitian ada beberapa tahapan yang harus dilakukan, tahapan kerja ini merupakan tahapan yang harus dilewati dan dikerjakan sesuai dengan pokok masalah agar tidak keluar jalur dari batasan masalah yang ditentukan dan penelitian ini berjalan dengan baik(M.Hasyim Siregar, S.Kom., 2018). Pada kerangk penelitian yang dipakai yaitu mempelajari literatur, mengumpulkan data, menganalisa data, menganalisa metode $\mathrm{K}$ Means, menguji hasil, dan menganalisa hasil.

\subsection{KDD (Knowledge Discovery In Database) \\ Data mining dan knowledge discovery in} database (KDD) sering digunakan secara bergiliran untuk menjelaskan proses penggalian informasi tersembunyi dalam suatu basis data yang besar(Nasari \& Darma, 2015).

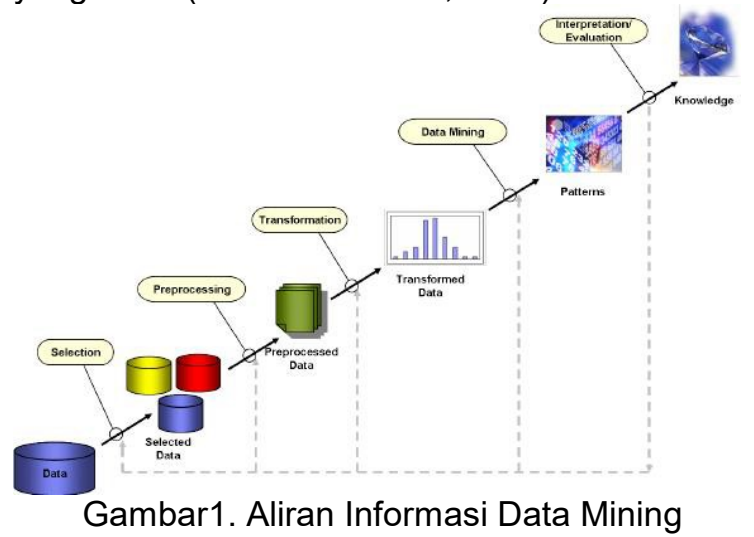

a. Data Mining

Data Mining merupakakn analisa terhadap sebuah data untuk menemukan hubungan yang nyata serta menyimpulkannya dengan yang belum diketahui sebelumnya dengan cara terkini sehingga mudah dipahami dan dapat berguna bagi pemilik data tersebut(Widodo, 2004).

\section{b. Clustering}

Clustering merupakan metode yang digunakan untuk membagi suatu rangkaian data menjadi beberapa kelompok berdasarkan kesamaankesamaan yang telah ditentukan sebelumnya(Dhuhita, 2015).

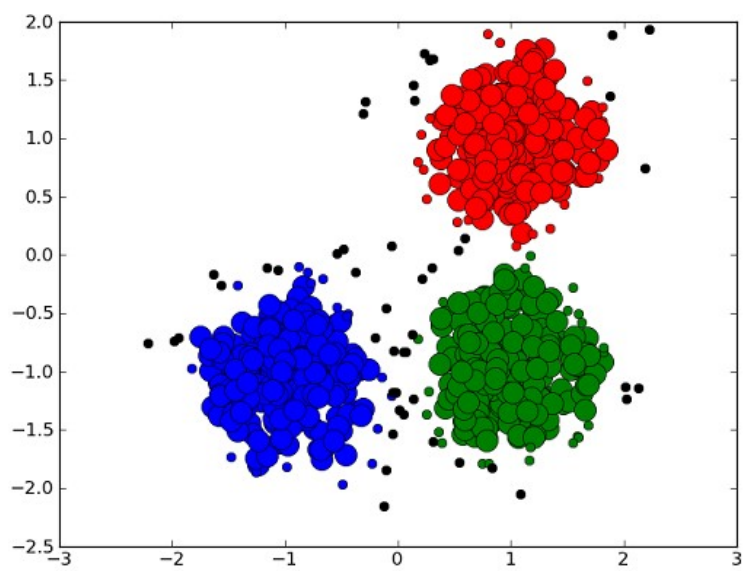

Gambar 2. Contoh Pada Clustering c. Algoritma K-Means

Algoritma K-Means merupakan suatu algoritma yang membagi data kedalam kelompok sehingga data berkarakteristik sama dimasukan kedalam sat kelompok yang sama dan data yang berkarakteristik berbeda dikelompokkan kedalam bagian kelompok yang lain(Prasetyo, 2012).

Data clustering menggunakan metode K-Means ini secara umum dilakukan dengan algoritma dasar sebagai berikut(Alfian, Sandi, Raharjo, \& Putra, 2018): 
1. menentukan berapa jumlah cluster

2. menempatkan data ke dalam cluster secara acak

3. Hitung centroid rata-rata dari data yang ada di masing-masing cluster

4. menempatkan masing-masing data ke centroid/rata-rata terdekat

5. Kembali ke langkah 3, apabila masih ada data yang berpindah cluster atau apabila perubahan nilai centroid, ada yang di atas nilai threshold yang ditentukan atau apabila perubahan nilai pada object function yang digunakan di atas nilai threshold yang ditentukan.

\section{d. Cleaning}

Sebelum masuk ke dalam proses data mining, perlu dilakukan proses pembersihan pada data yang menjadi focus KDD. Proses pembersihan bermaksud untuk membuang duplikasi data, memeriksa data yang inkosisten, dan memperbaiki kesalahan pada data, seperti kesalahan cetak (tipografi)(Nasari \& Darma, 2015).

\section{e. Interpretation / Evaluation}

Pola informasi yang dihasilkan dari proses data mining perlu ditampilkan dalam bentuk yang dapat dimengerti oleh pihak yang berkepentingan. Langkah ini merupakan bagian dari proses KDD yang disebut interpretation. langkah ini mencakup pemeriksaan apakah pola atau informasi yang ditemukan bertentangan dengan fakta atau hipotesis yang ada sebelumnya(Nasari \& Darma, 2015).

\section{HASIL DAN PEMBAHASAN}

\section{Pengumpulan Data}

Data yang di uji bersumber dari data penjualan pada fachry property land, dalam data yang diambil terdapat atribut-atribut seperti nama marketing, target penjualan, satuan, unit terjual, harga, persentase penjualan, dan lokasi perumahan yang terjual. Periode yang digunakan dari data tersebut bulan januari sampai desember 2019.

2. Praproses Data

Pada tahapan ini data yang telah dikumpulkan akan masuk pada tahap pemilihan atribut yang akan dipilih untuk di olah nanti nya.

Tabel 1. Tabel Penjualan

\begin{tabular}{|c|c|c|}
\hline $\mathrm{NO}$ & Nama Attribut & Keterangan \\
\hline 1 & $\begin{array}{l}\text { Nama } \\
\text { Marketing }\end{array}$ & $\begin{array}{l}\text { Nama } \\
\text { marketing } \\
\text { penjualan }\end{array}$ \\
\hline 2 & Jumlah Target & $\begin{array}{l}\text { Jumlah target } \\
\text { yang harus } \\
\text { tercapai. }\end{array}$ \\
\hline 3 & Satuan & Unit/rumah \\
\hline 4 & Unit terjual & $\begin{array}{l}\text { Unit yang } \\
\text { berhasil dijual } \\
\text { oleh marketing }\end{array}$ \\
\hline
\end{tabular}

5

6

Harga

Persentasi

Pencapaian

Harga rumah

diakur diakumulasikan dengan unit terjual dan harga

7

Lokasi

Letak

Perumahan yang tersedia

\section{Proses Klastering menggunakan} algoritma K-Means.

Tahapan dalam pemakaian algoritma Kmeans adalah menentukan banyaknya cluster, cluster yang akan dibuat sebanyak 3 cluster. Banyaknya cluster harus lebih kecil dari pada banyaknya data.

\begin{tabular}{|l|l|l|l|}
\hline Attribute & cluster_0 & cluster_1 & cluster_2 \\
\hline Unit Terjual & 0.249 & 2.281 & 4.459 \\
\hline Harga (Rp) & 40595135.908 & 400179856.115 & 784672131.148 \\
\hline Persentasi Pencapaian & 10.250 & 100.259 & 196.361 \\
\hline
\end{tabular}

\section{Gambar 3. Centroid Table}

Gambar 3 adalah gambar centroid table yang dihasilkan menggunakan aplikasi Rapid Miner Studio v.9.2. untuk bagaimana mendapatkan hasil tersebut akan dijelaskan dibawah ini.

Pada gambar 4 merupakan halaman utama dari aplikasi RapidMiner Studio v.9.2 saat pertama kali membuka aplikasi setelah proses loading selesai terlihat pada gambar berikut:

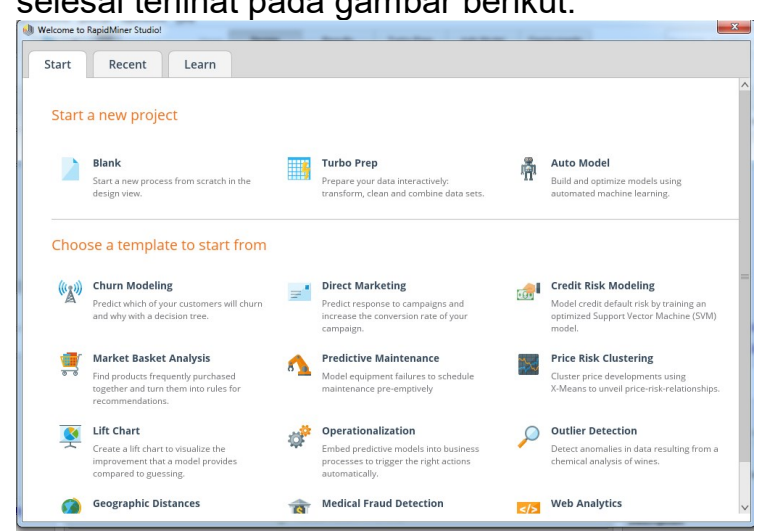

Gambar 4. Halman Utama Rapid Miner Studio V 9.2.

Pada tampilan halaman utama ada tiga menu yang akan digunakan yaitu :

1. Icon New Process berfungsi untuk membuat halaman proses kerja Data Mining yang baru.

2. Open Process berfungsi untuk membuka proses yang sudah ada direpository sebelumnya.

3. Learn berisikan petunjuk-petunjuk menggunakan RapidMiner Studio v.9.2. 
Berikut ini adalah tampilan New Process yang akan digunakan untuk memulai proses kerja baru terlihat pada gambar 5

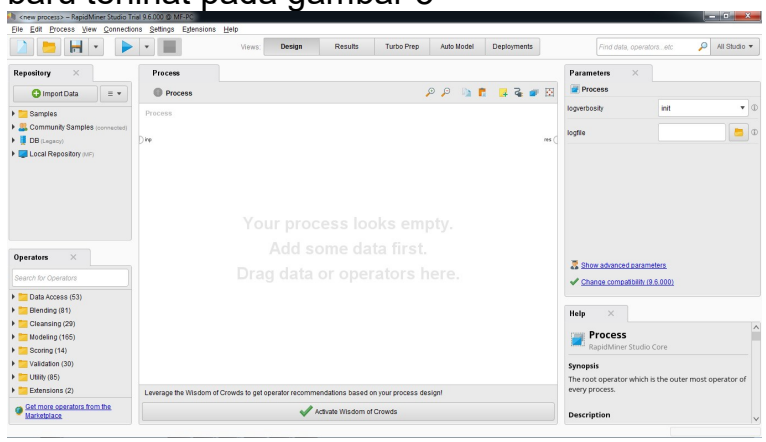

Gambar 5. New Process RapidMiner Studio v.9.2

Tampilan new process adalah untuk membuat halaman kerja pada RapidMiner Studio v.9.2. Import data dilakukan untuk memasukkan data yang akan diuji dalam bentuk format .x/s atau .x/sx. Berikut adalah cara untuk melakukan import file Microsoft Excel. Untuk membuat mengimport data yang akan diproses, maka dilakukan New process, dengan cara klik kanan $>$ Insert Operator > Data Access > Files > Read $>$ Read Excel.

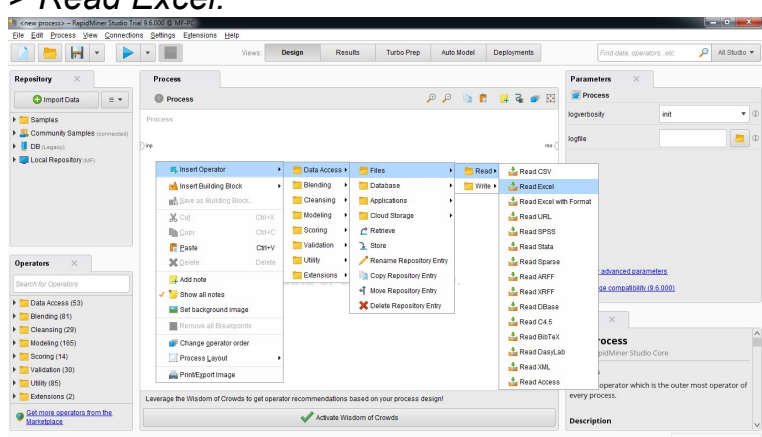

Gambar 6. Tampilan Import Data Dengan Membuat Operator Baru

Setelah selesai maka akan tampil read excel pada RapidMiner Studio v.9.2, Seperti terlihat pada Gambar 8. Setelah itu lanjutkan dengan mngklik Tab Import Configuration Wizard untuk melakukan menginputkan data dari Microsoft Excel (dengan format .x/s, atau .x/sx).

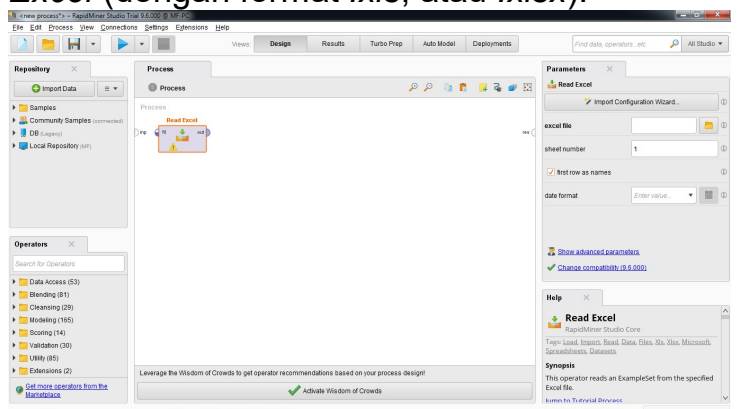

Gambar 7 Tampilan Operator Baru Read Excel.
Dalam melakukan import data pada aplikasi RapidMiner Studio v.9.2 terdiri dari 3 tahap, adapun langkah-langkahnya sebagai berikut: 1. Data Import Wizard - Step 1 of 3

Tahap pertama adalah mencari lokasi file yang sudah ada sebelumnya dengan format .x/sx . atau $x / s$, pilih dan kemudian simpan. Pada pengujian ini data yang akan diuji disimpan dengan nama PENJUALAN.xIsx lalu pilih diklik, seperti Gambar 8

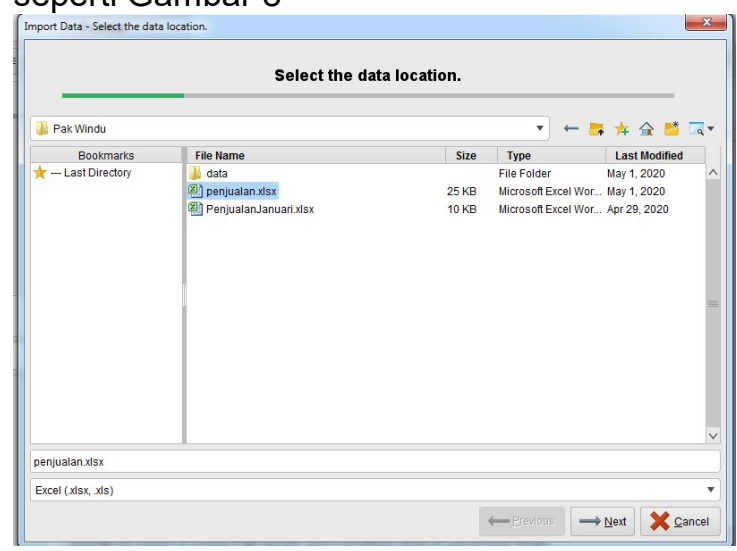

Gambar 8. Tampilan Data Import Wizard - Step 1 of 4

2. Data Import Wizard - Step 2 of 3

Kemudian pilih next maka lanjut ke tahap berikutnya yaitu impor wizard step 2 of 4 . Pada tahap ini akan dipilih Sheet yang berisikan sumber data pada Microsoft Excel yang digunakan. Maka akan terlihat data import wizard seperti terlihat pada gambar 9 .

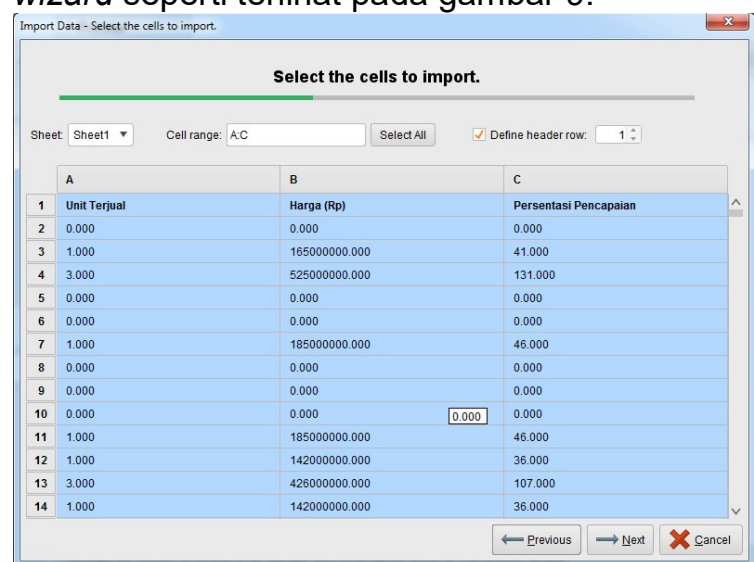

Gambar 9 Tampilan Data Import Wizard - Step

$$
2 \text { of } 41
$$

3. Data Import Wizard - Step 3 of 3

Pada Step 3, tahap ini merupakan tahap penentuan tipe data dan atribut. Sebenarnya RapidMiner Studio akan memberikan tipe data yang tepat secara otomatis. Namun, jika kita merasa tipe data yang diberikan RapidMiner Studio tidak cocok, kita bisa mengubahnya. Kumudian klik tombol Next . 


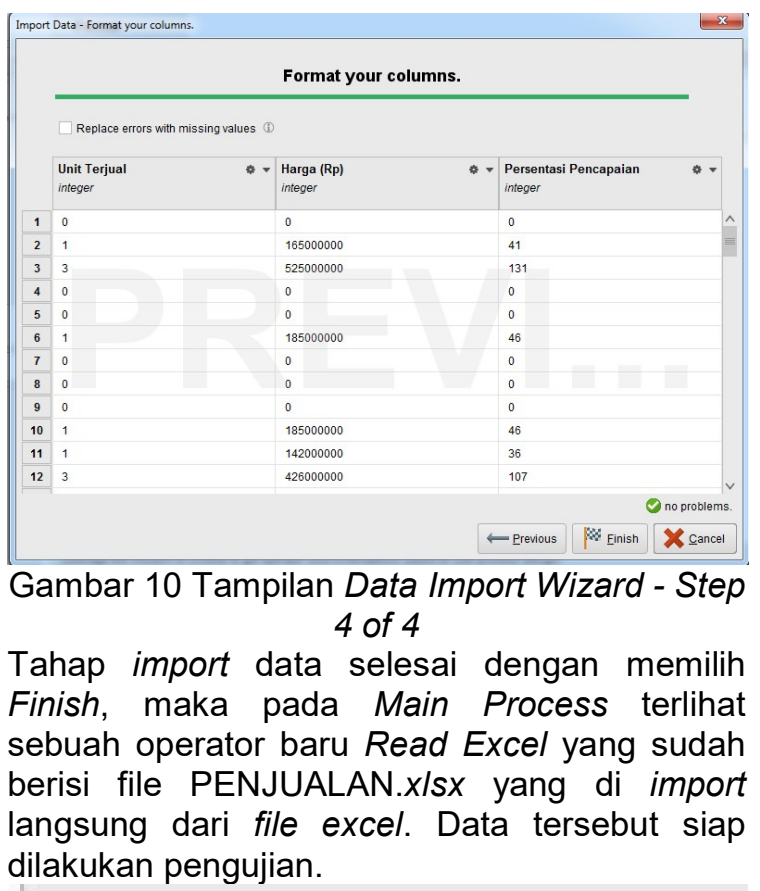
dilakukan pengujian.

\section{Process}

\section{Read Excel}

inp

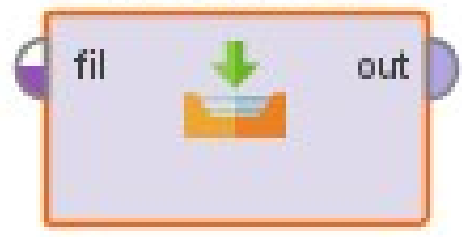

Gambar 11 Tampilan Operator Data Siap Import

Pada gambar 12 menampilkan data yang sudah di import, sehingga tombol pada operator read excel tidak ada lagi tanda seru warna kuning (menandakan operator telah berisi data dan siap diolah).

Langkah selanjutnya adalah menambahkan operator K-Means dengan cara klik kanan $>$ Insert Operator ->Modeling ->Segmentation $>$ K-Means.

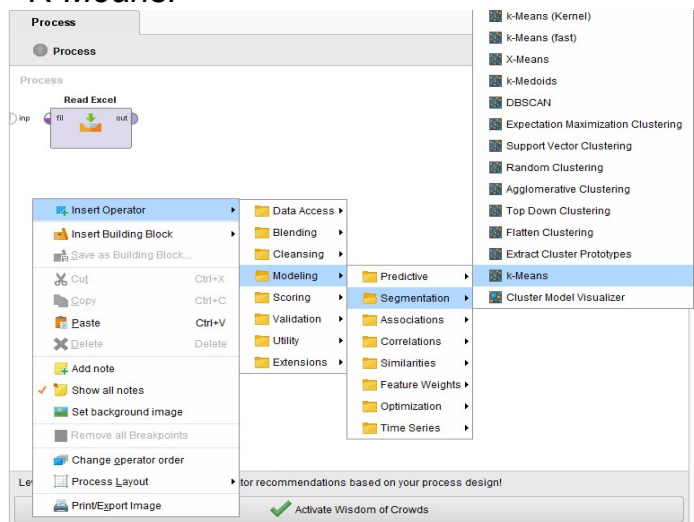

Gambar 12. Menambahkan Operator K-Means
Hubungkan data dengan clustering k-means untuk mengetahui output ke arah result. Apabila sudah terhubung maka tentukan jumlah cluster dan maksimal runs yang diberikan. Terakhir klik Tombol Play, seperti pada Gambar 13

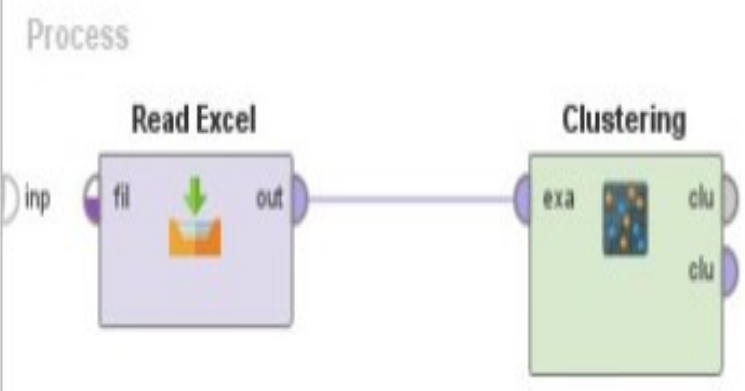

Gambar 13 Tampilan Untuk Proses K-Means Selanjutnya melakukan pengaturan algoritma K-Means, yang diatur pada menu Parametere Clustering K-Means, seperti terlihat pada gambar 14

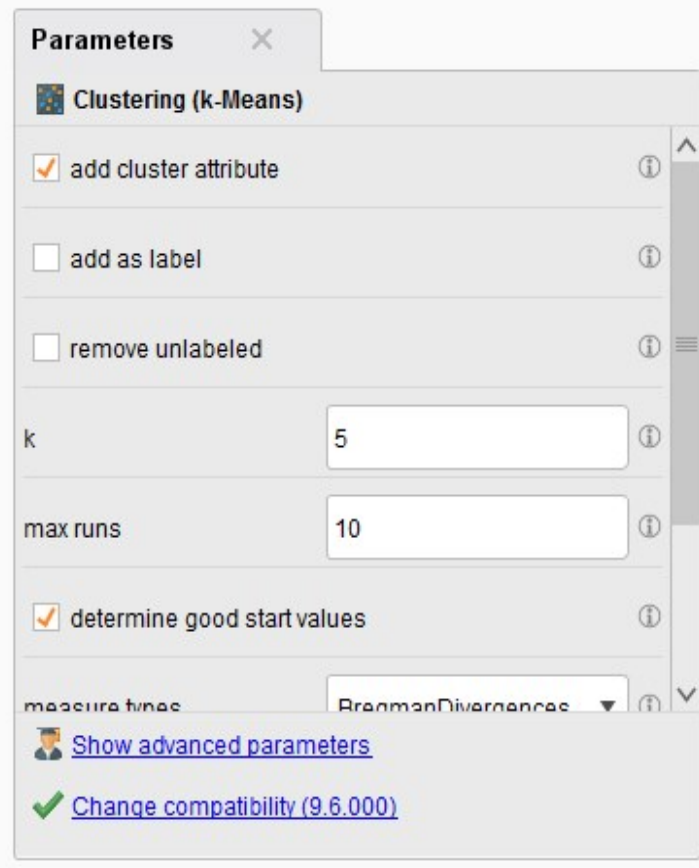

Gambar 14 Penentuan Jumlah Cluster

Pada gambar 14 di atas dilakukan pengaturan nilai $k$, di mana $k$ merupakan nilai yang digunakan untuk menentukan jumlah cluster yang akan dibentuk. Di sini jumlah cluster yang akan dibentuk adalah sebanyak 3 cluster sesuai tingkatan bahaya yaitu rendah, sedang dan tinggi.

Setelah proses running, akan tampil Example Set (Read Excel), seperti yang terlihat pada Gambar 15. 


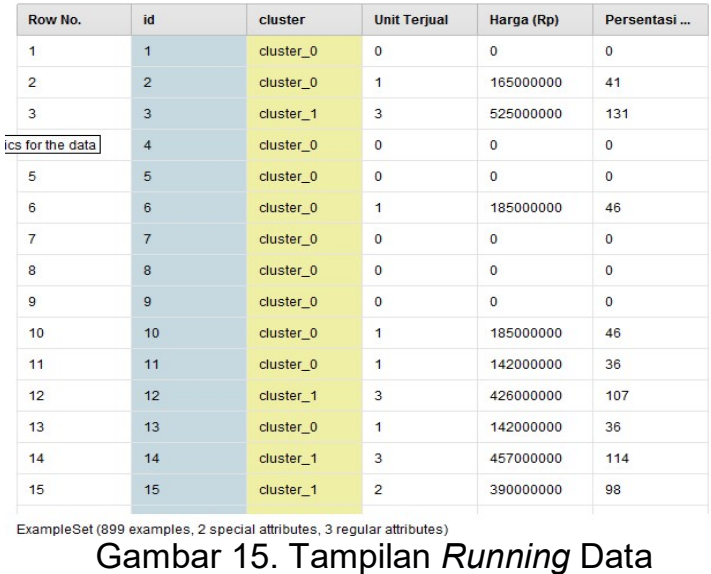

1. ExampleSet

Pada ExampleSet dapat dilihat beberapa tampilan hasil cluster, yaitu Data View. Data View merupakan tampilan hasil cluster data secara keseluruhan sesuai dengan data yang telah diinputkan

Chart merupakan tampilan grafik hasil pengelompokan atau cluster sampel data nilai mata pelajaran ujian nasional dengan 3 cluster.

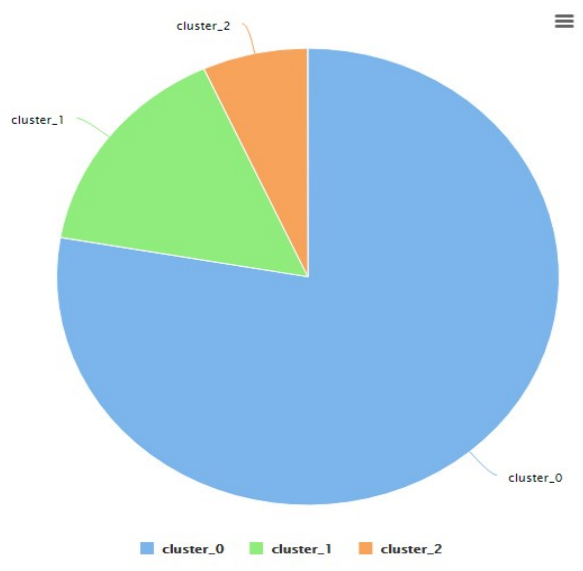

Gambar 16. Tampilan Pie pada Chart

2. Cluster Model (Clustering)

Pada Cluster Model (Clustering) dapat dilihat beberapa tampilan hasil cluster, yaitu Text View yang merupakan tampilan hasil pengelompokan berdasarkan cluster dan jumlah anggotanya. Tampilan Text View akan terlihat pada gambar 17.

\section{Cluster Model}

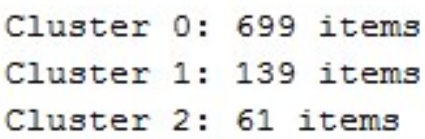

Total number of items: 899

Gambar 17. Tampilan Text View
Pada gambar 17 dapat kita lihat data berupa : cluster 0 yang memiliki kategori tidak memenuhi target mendapatkan jumlah sebanyak 699 items.

Cluster 1 yang memiliki kategori belum memenuhi target mendapatkan jumlah sebanyak 139 items.

Cluster 2 yang memiliki kategori memenuhi target mendapatkan jumlah sebanyak 61 items.

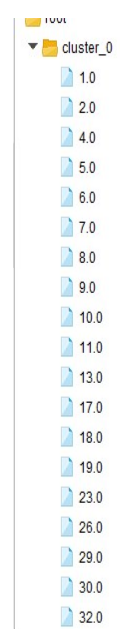

Gambar 18. Tampilan Folder View

Folder View merupakan tampilan data bagianbagian cluster secara keseluruhan, dimana masing - masing anggota cluster menampilkan field.

\section{KESIMPULAN}

Berdasarkan uraian yang sudah dikemukakan pada sebelumnya, maka dapat ditarik kesimpulan Metode Clustering dengan menggunakan algoritma K-Means dapat digunakan untuk mengelompokkan karyawan berdasarkan kinerjanya, yaitu tidak memenuhi target, belum memenuhi target, dan sudah memenuhi target. Sehinga pihak perusahaan dapat mengevaluasi kinerja karyawan yang tidak atau belum memenuhi target panjualan. Apa lagi dapat kita simpulkan bahwa data rekapan karyawan tersebut hanya sebanyak 61 kali dapat mencapai target penjualan.

Peneliti menyadari adanya kekurangan dalam penulisan ini, karena keterbatasan penulis baik dalam hal waktu maupun pengetahuan. Dalam rangka memperbaiki kekurangan dan untuk penyempurnaan penelitian ini penulis memberikan beberapa saran Untuk penelitian selanjutnya dapat dilakukan dengan data yang lebih banyak dan parameter yang lebih banyak lagi serta Untuk memaksimalkan waktu proses clustering dengan algoritma K-Means, penelitian selanjutnya dalam hal pengektrasian data tercapainya target penjualan menerapkan metode Data Mining dengan algoritma yang berbeda. 


\section{REFERENSI}

Alfian, T., Sandi, A., Raharjo, M., \& Putra, J. L. (2018). CLUSTERING KESETIAAN PELANGGAN E-RITEL DENGAN MODEL RFM, 14(2), 239-246. Retrieved from https://ejournal.nusamandiri.ac.id/index.ph $\mathrm{p} /$ pilar/article/view/74

Asroni Asroni, R. A. (2015). Penerapan Metode K-Means Untuk Clustering Mahasiswa Berdasarkan Nilai Akademik Dengan Weka Interface Studi Kasus Pada Jurusan Teknik Informatika UMM Magelang, 18(1), 76-82. Retrieved from https://www.researchgate.net/publication/3 29831347_Penerapan_Metode_KMeans_Untuk_Clustering_Mahasiswa_Be rdasarkan_Nilai_Akademik_Dengan_Wek a_Interface_Studi_Kasus_Pada_Jurusan Teknik_Informatika_UMM_Magelang_Impl ementation_Method_for_KMeans Clusteri

Dhuhita, W. M. P. (2015). CLUSTERING MENGGUNAKAN METODE $K$ MEANS UNTUK MENENTUKAN STATUS GIZI BALITA, 15(2). Retrieved from https://www.neliti.com/id/publications/1037 65/clustering-menggunakan-metode-kmean-untuk-menentukan-status-gizi-balita

Garg, S. K. dan K. (2016). Document Clustering using Improved K-means Algorithm. International Journal of Engineering Research and General Science, 4(3). Retrieved from http://www.indianjournals.com/ijor.aspx?ta rget $=$ ijor:ijrss $\&$ volume $=6 \&$ issue $=9 \&$ article $=$ 017

Jayant Tikmani, Sudhanshu Tiwari, S. K. (2015). $\mathrm{n}$ Approach to Customer Classification using k-means. International Journal of Innovative Research in
Computer and Communication Engineering, 3(11). Retrieved from http://www.ijircce.com/upload/2015/novem ber/29_An.pdf

M.Hasyim Siregar, S.Kom., M. K. (2018). KLASTERISASI PENJUALAN ALATALAT BANGUNAN MENGGUNAKAN METODE K-MEANS, 1(2), 83-91. Retrieved from https://ejournal.uniks.ac.id/index.php/JTO S/article/view/24

Mardalius. (2018). PENGELOMPOKAN DATA PENJUALAN AKSESORIS MENGGUNAKAN ALGORITMA KMEANS, IV(2), 401-411. Retrieved from https://www.researchgate.net/publication/3 30609314 PEMANFAATAN RAPID MIN ER_STUDIO_82_UNTUK_PENGELOMP OKĀN DATA PEN $\bar{E}$ JUALĀN AKSESORIS MENGGGUNĀKAN_ALGORITMA_KMEANS

Nasari, F., \& Darma, S. (2015). PENERAPAN K-MEANS CLUSTERING PADA DATA PENERIMAAN MAHASISWA BARU, 6-8. Retrieved from https://www.ojs.amikom.ac.id/index.php/se mnasteknomedia/article/viewFile/837/801

Ong, J. O. (2013). IMPLEMENTASI ALGORITMA K-MEANS CLUSTERING UNTUK MENENTUKAN STRATEGI MARKETING, (April), 10-20. Retrieved from

http://journals.ums.ac.id/index.php/jiti/articl e/view/651

Prasetyo, E. (2012). Data Mining Konsep dan Aplikasi Menggunakan Matlab. Yogyakarta: CV. Andi Offset.

Widodo. (2004). Psikologi Belajar. jakarta: Rineka Cipta. 